\title{
Solvent-Induced Crystallization and Interaction Parameter of the Blends of Bisphenol A Polycarbonate and Poly(phenyl methacrylate)
}

\author{
Dongkyu PARK and Jin-Who HoNG* \\ $R \& D$ Center, Hyundai Petrochemical Co., Ltd., Daesan, Chungchungnam-do 356-870, Korea \\ * Department of Polymer Science \& Engineering, Chosun University, \\ Kwangju 501-759, Korea
}

(Received February 21, 1997)

\begin{abstract}
Blends of bisphenol A polycarbonate (PC) and poly(phenyl methacrylate) (PPMA) were crystallized by tetrahydrofuran (THF) solvent to investigate the phenomena of solvent-induced crystallization. The optimum conditions for solvent induced crystallization in PC have been determined. Interaction parameter has been calculated based on the melting point depression method to estimate the extent of miscibility. A negative interaction parameter $\left(\chi_{12}=-0.21\right)$ obtained from the melting point depression method suggests that there is some attractive interaction between the blend components. KEY WORDS Blend/Solvent Induced Crystallization/Interaction Parameter /
\end{abstract}

Polycarbonate (PC) has been widely used both as a blend partner and by itself because it has outstanding engineering properties. Furthermore, due to its remarkable transparency, $\mathrm{PC}$ has been recognized as a suitable plastic for optical storage disc. ${ }^{1-4}$ The criteria of such optical materials ${ }^{4}$ require low birefringence, low hygroscopicity, high transmission, dimensional stability, processability, and good mechanical properties. These stringent requirements can be fulfilled by specially designed polycarbonates. ${ }^{2}$ However, $\mathrm{PC}$ shows a large positive birefringence, ${ }^{5}$ which might cause optical distortion, owing to the presence of aromatic groups in the main chain. This positive birefringence can be eliminated substantially by blending with a polymer which has negative birefringence and can form a single phase with the constituent polymer. Poly(phenyl methacrylate) (PPMA) may be chosen as the blend partner of PC to form a miscible birefringence-free blend. For this reason, the birefringence-free composition of the PC/PPMA blend may be determined. The copolymers of PPMA and their blends often been reported to be used as optical lenses ${ }^{6-16}$ and optical disk recording materials ${ }^{17}$ because of the high refractive index (1.5706) and high transparency of PPMA. But PPMA is very brittle and has low dimensional and thermal stability. ${ }^{18}$ On the other hand, PC shows tough and ductile properties, good processability, thermal stability, and good electrical properties, but its poor scratch resistance and thermal stresscracking with its large birefringence are disadvantages. It can be expected, therefore, that the drawbacks of each pure component can be overcome by blending the two components. By controlling the compositions of the blends, the improvement of physical properties may be achieved.

We have demonstrated that the blends of the PC/ PPMA are completely miscible ${ }^{19}$ and the birefringence and tensile properties of the blends were excellent. It is therefore of paramount importance to identify the origin of miscibility and to estimate the extent of miscibility by determining $\chi_{12}$ interaction parameter. It has been known that solvent-induced crystallization can occur in PC. In this paper, the phenomena of solvent-induced crystallization and the melting behavior of $\mathrm{PC}$ in the blends have been investigated. Subsequently, $\chi_{12}$ interaction parameter was calculated based on the melting point depression method.

\section{EXPERIMENTAL}

The components of the blends used in this study were bisphenol A PC and PPMA. Their characteristics are tabulated in Table I. The molecular weight and polydispersity of the materials were measured by gel permeation chromatography (Waters, Model GPC-150) based on poly(methyl methacrylate) standard.

Various compositions of PC and PPMA were dissolved in tetrahydrofuran (THF) by stirring at ambient temperature. At this time the polymer concentration of the ternary solution was $5 \mathrm{wt} \%$. After completely dissolving the polymers the solution was co-precipitated by adding the solution slowly ( $\left.c a .0 .3 \mathrm{ml} \mathrm{s}^{-1}\right)$ to a nonsolvent, methylalcohol, whose volume is 5 times as that of the solution. During the precipitating the non-solvent was stirred by a stirring bar to accelerate the precipitation. The precipitates was dried for 3 days in a vacuum oven which was maintained at $70^{\circ} \mathrm{C}$ and at a reduced pressure.

The dried precipitates obtained from the solution blending were compressed by a compression molding machine to get a thin sheet (thickness, $c a .0 .2 \mathrm{~mm}$ ). The thin sheet was soaked in THF contained in a sealed flask and maintained 7 days at room temperature $\left(23 \pm 2^{\circ} \mathrm{C}\right)$. At this time the volume ratios of the specimen/THF were $1 / 1.5,1 / 3$, and $1 / 4.5$. The crystallized samples were dried for 3 days in a vacuum oven controlled at $70^{\circ} \mathrm{C}$ and a reduced pressure. The solvent-induced crystallized sample for annealing was encapsulated in a DSC aluminum pan and further crystallized by heat in the vacuum oven.

Another crystallization was done by THF vapor. The same kind of thin sheet was suspended in a capped flask whose bottom is filled with THF for 7 days at room temperature $\left(23 \pm 2^{\circ} \mathrm{C}\right)$. The dry condition for crystallized samples is the same as the above condition. 
Table I. Material characteristics

\begin{tabular}{cccc}
\hline Polymer & Supplier & $M_{n}$ & $M_{w} / M_{n}$ \\
\hline PC & $\begin{array}{c}\text { Scientific Polymer } \\
\text { Products Co. }\end{array}$ & $2.3 \times 10^{4}$ & 1.5 \\
PPMA & $\begin{array}{c}\text { Scientific Polymer } \\
\text { Products Co. }\end{array}$ & $1.1 \times 10^{5}$ & 2.1 \\
\hline
\end{tabular}

Table II. Compression molding temperature of the press for different blend compositions

\begin{tabular}{cc}
\hline Compositions (PC/PPMA) & Molding temperature $/{ }^{\circ} \mathrm{C}$ \\
\hline PC & $220 \pm 3$ \\
$90 / 10$ & $215 \pm 3$ \\
$70 / 30$ & $206 \pm 3$ \\
$50 / 50$ & $197 \pm 3$ \\
$30 / 70$ & $190 \pm 3$ \\
$10 / 90$ & $183 \pm 3$ \\
PPMA & $178 \pm 3$
\end{tabular}

The thermal analysis was done on a Du Pont 910 differential scanning calorimeter coupled with a Du Pont 9900 thermal analyzer. Each sample ( $c a .11 \mathrm{mg}$ ) was encapsulated in an aluminum pan using a press. The encapsulated sample was put in a heating/cooling cell with blank aluminum pan as a reference. The cell was maintained under nitrogen circulation during its running. Before running the sample the cell was calibrated using indium as a standard. The heating rate of $20^{\circ} \mathrm{C}$ was chosen arbitrarily.

Every sheet-shape specimen was prepared by a compression molding machine (Carver Laboratory Press Model C). Each molded sample was quenched by cool tap water immediately after taking out from the press. Molding temperature of the press was determined according to the blend composition and shown in Table II.

\section{RESULTS AND DISCUSSION}

The process of solvent-induced crystallization (SINC) probably occurs in the following sequence. A solvent penetrates in a polymer by diffusion. The polymersolvent interaction causes enhanced mobility of the polymer by interrupting the intersegmental forces. The interaction between the solvent and polymer causes high mobility of the polymeric segments when the polymersolvent interaction is strong enough, then the polymer molecules become capable of rearranging into a more thermodynamically lower energy state, i.e., the crystal state. In other words, SINC could result from the process of partial dissolution to form a concentrated solution followed by later crystallization and ejection of solvent from a crystal lattice. The sorption of the solvent by the polymer induces a lowering of the $T_{\mathrm{g}}$ and $T_{\mathrm{m}}$ by a plasticizing effect. Thus SINC occurs at temperature much lower than those required for the dry polymer.

Polycarbonate cannot crystallize easily due to its stiff backbone chain consisting of phenyl groups. However, it can crystallize either by prolonged heating or by solvent inducement at room temperature. The crystallization tendency of PC is activated by solvents. For example,

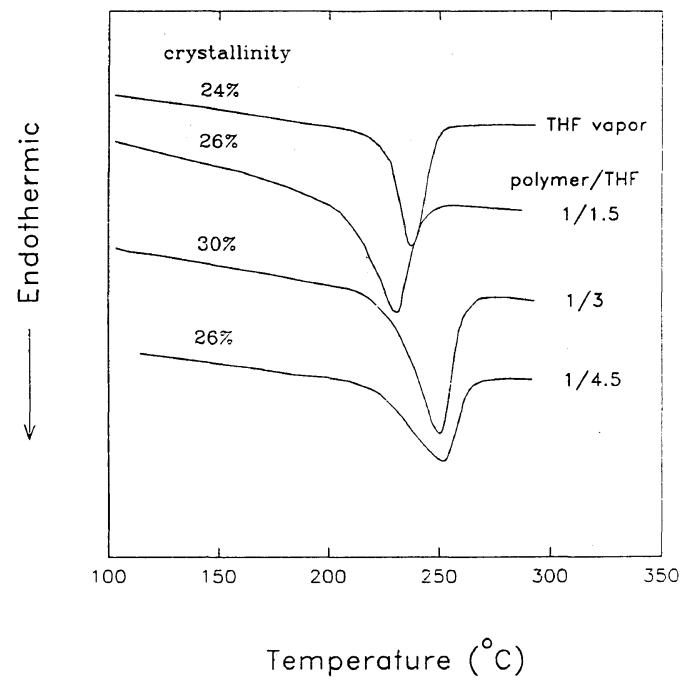

Figure 1. The DSC thermogram of PC crystallized by THF with different conditions.

by slow evaporation of solvent from cast film ${ }^{20}$ or by treatment with swelling agents such as ethylacetate or acetone, PC can crystallize.

Various pure PC polymers from different crystallization conditions were compression molded into thin sheets (thickness, $0.2 \mathrm{~mm}$ ) and then soaked in THF solvent for 7 days at room temperature $\left(23^{\circ} \mathrm{C}\right)$. If the amount of THF is small, the solvent-induced crystallization of PC may be incomplete. On the other hand, excessive amount of THF can dissolve PC completely. Hence, it is essential to examine an optimum condition for the SINC of pure PC polymers. The effect of solvent content on the crystallizability of PC has been studied by soaking the pure $\mathrm{PC}$ polymers in THF in the volume ratio of $1 / 1.5,1 / 3$, and $1 / 4.5$ blend/THF. Also neat PC was crystallized by THF vapor for comparison. Figure 1 illustrates the extent of crystallization of $\mathrm{PC}$ for the different conditions. As shown in the figure, the PC can also crystallize only by THF vapor but the crystallinity is less than that of the PC crystallized by soaking in THF. The crystallinity $(\beta)$ was calculated by eq 1 :

$$
\beta=\Delta H^{\mathrm{f}} / \Delta H_{0}^{\mathrm{f}}
$$

where $\Delta H^{\mathrm{f}}$ is the enthalpy of PC observed in the DSC melting peak and $\Delta H_{0}^{\mathrm{f}}\left(=132 \mathrm{Jg}^{-1}\right)$ is the enthalpy of melting of purely crystalline PC. The PC crystallized by soaking in THF whose volume is 3 times as large as that of PC exhibits the largest melting peak and higher melting temperature. At 1/4.5 ratio the crystallinity reduces probably due to a partial solution of crystals in excess THF. The $T_{\mathrm{m}}$ remains the same as that of $1 / 3$ ratio, implying that only more perfect crystallites survive. The polarized optical micrograph of PC crystallized by THF vapor has been studied. However, the crystalline structure of the PC was too small to be identified under the optical microscope. Therefore, alternatively light scattering patterns were investigated to elucidate the crystalline structure of PC. Figure 2 demonstrates the scattering patterns of a small-angle light scattering (SALS). The appearance of large four-leaf clover pattern but relatively low robe intensity of scattered light in $H_{\mathrm{v}}$ pattern insinuates that the crystals are incom- 

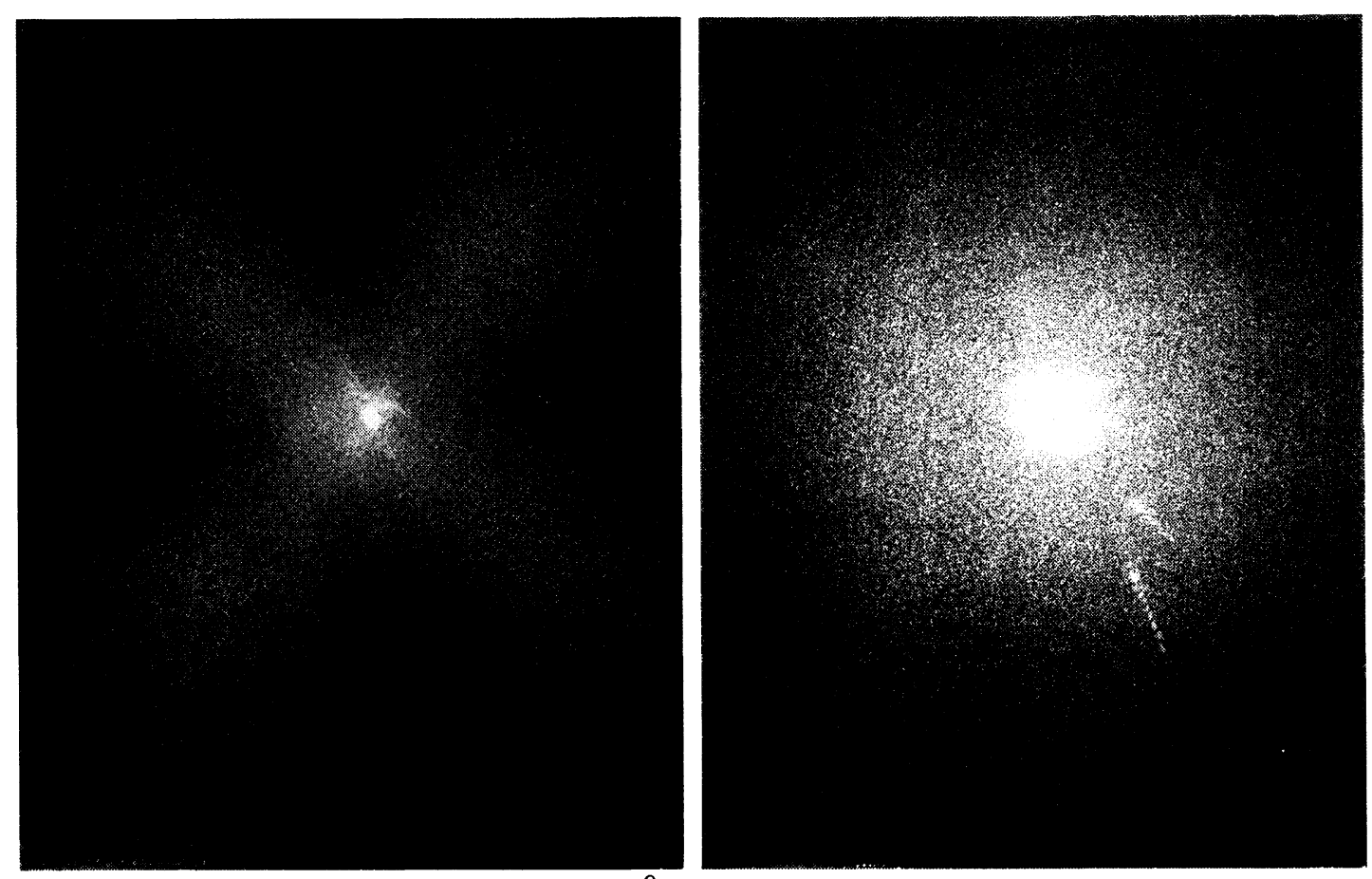

$30^{\circ}$

$\mathrm{H}_{\mathrm{v}}$

$\mathbf{V}_{\mathbf{v}}$

Figure 2. SALS $H_{\mathrm{v}}$ and $V_{\mathrm{v}}$ patterns of PC crystallized by THF vapor.

plete spherulites. The measured radius of the crystal was $1.6 \mu \mathrm{m}$ indicating the relatively small size of crystal. As spherulites become perfect, the robe intensity would increase. It is known that spherulites develop from rodlike precursors which grow into sheaf-like structures and then consequently into spherulites. ${ }^{21}$ Therefore, the crystal structure may be sheaf-like.

In order to investigate the effect of annealing time on the PC crystallized by THF, the SINC PC was encapsulated in DSC aluminum pan and annealed in a vacuum oven maintained at $190^{\circ} \mathrm{C}$ for $1,2,4$, and 6 days respectively. The annealing temperature $\left(190^{\circ} \mathrm{C}\right)$ was chosen from the literatures, ${ }^{22,23}$ in which maximum crystallinity of PC was achieved at $190^{\circ} \mathrm{C}$ for 8 days. Figure 3 shows that the melting point of $\mathrm{PC}$ increases up to the annealing time of 2 days. After that time no change of melting temperature was observed. The effect of annealing temperature on the melting temperature of the SINC PC was investigated by soaking the polymer in THF in the volume ratio of $1 / 3$ at $190^{\circ} \mathrm{C}$ for 3 days. The annealing time of 3 days was chosen to minimize the possible chemical reaction or degradation of the PC. As expected, the melting temperature of the $\mathrm{PC}$ begins to increase at about $150^{\circ} \mathrm{C}$ of annealing temperature which is around the $T_{\mathrm{g}}$ of PC as shown in Figure 4. The higher the annealing temperature $\left(T_{\mathrm{c}}\right)$, the higher the melting point $\left(T_{\mathrm{m}}\right)$ of the PC was obtained. This increasing $T_{\mathrm{m}}$ with $T_{\mathrm{c}}$ will continue up to the equilibrium melting point of PC. Figure 4 also shows that the degree of crystallinity of PC increases but small amount up to $200^{\circ} \mathrm{C}$ with increasing annealing temperature and then decreases from about $200^{\circ} \mathrm{C}$. This is because at over $200^{\circ} \mathrm{C}$ the amount of crystals melting will exceed that of crystals crystallizing.

For a miscible crystalline blend, the depression of melting point of a crystallizable polymer occurs due to the lower chemical potential of the crystallizable component in the mixed amorphous phase. This depression phenomenon may be used to gain valuable information about interactions between blend components.

The PC/PPMA blends were crystallized by soaking the blend sheet in THF in the volume ratio of $1 / 3$ (blend/THF). Figure 5 depicts the DSC thermogram of the SINC blends. As shown in Figure 6 which is the plot of $T_{\mathrm{m}}$ versus PPMA content, the melting temperature of the blends was systematically depressed as the composition of PPMA increases. The lowering of melting point can be attributed to the small size and imperfection of crystalline regions. ${ }^{24}$ Also the size of the melting peak become smaller gradually with the increasing PPMA content in the blends indicating that the degree of crystallinity decreases as the PPMA content increases. However, as can be seen in Figure 7, the blend of the 90/10 (PC/PPMA) shows a little bit higher degree of crystallinity than pure PC. It may be due to the nucleating effect $^{25,26}$ by PPMA. At 10\% PPMA content or below, there is a possibility that PPMA could act as a nucleating agent, thereby expedites the crystallization. However, the $T_{\mathrm{m}}$ of the $90 / 10$ composition was lowered as seen in Figure 6. This phenomenon might be construed as the effect of nucleating agent of PPMA. Too many number of nucleating agents dispersed in matrix can also limit the growing of spherulite due to the impingement among the growing spherulite themselves. Thus, the lower $T_{\mathrm{m}}$ of the blend reflects the smaller size of the crystallites.

The melting point depression of PC, which was evi- 


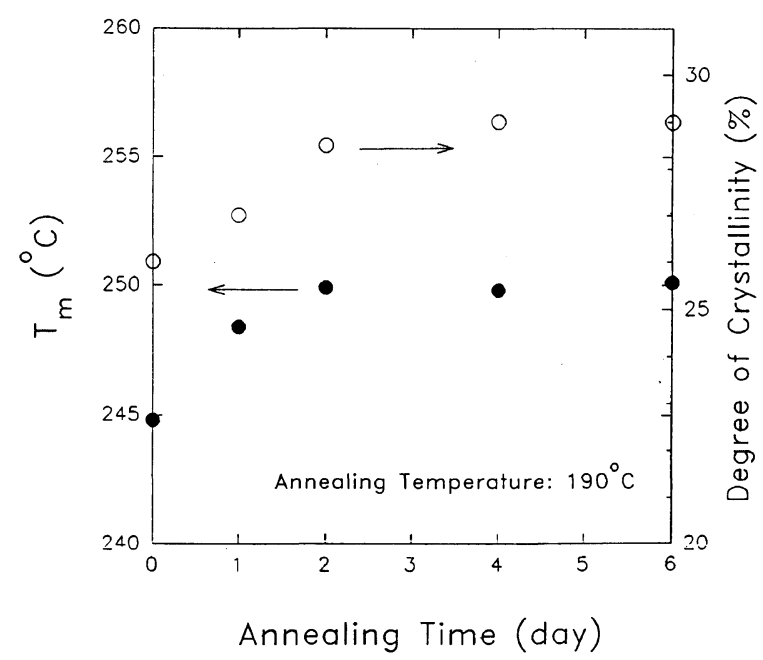

Figure 3. The effect of annealing time on the melting point and crystallinity of the SINC PC.

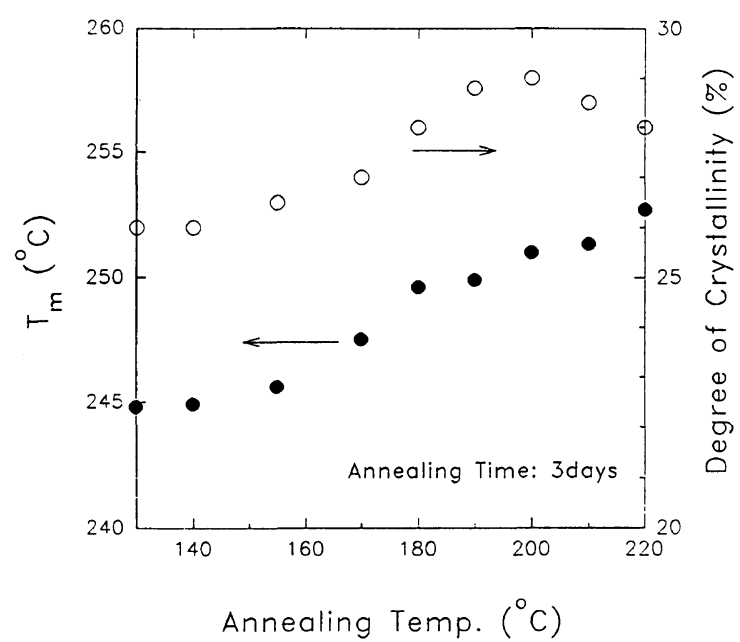

Figure 4. The effect of annealing temperature on the melting point and crystallinity of the SINC PC.

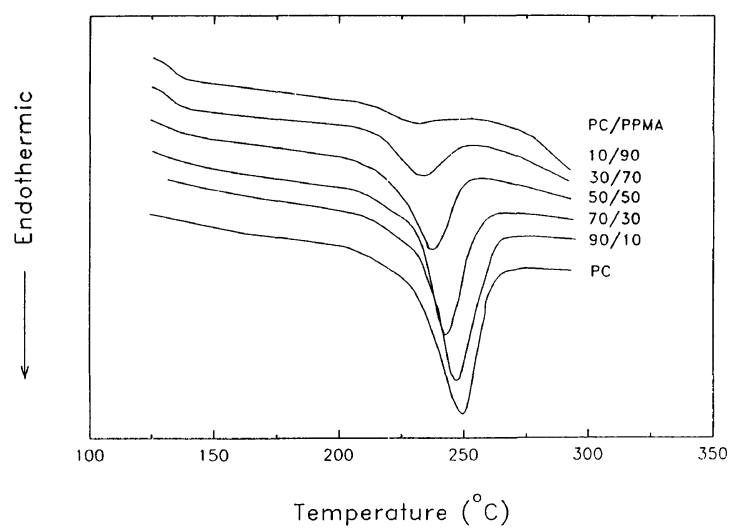

Figure 5. The DSC thermogram of PC/PPMA blends after solventinduced crystallization.

denced in the quasi-equilibrium experiments, intensifies progressively with increasing PPMA content. This phenomenon may be explained by considering the melting point depression observed in the crystalline polymerdiluent systems. However, unlike the case in the polymerdiluent systems, the interaction parameter, $\chi_{12}$, plays a decisive role on the melting behavior of the crystalline

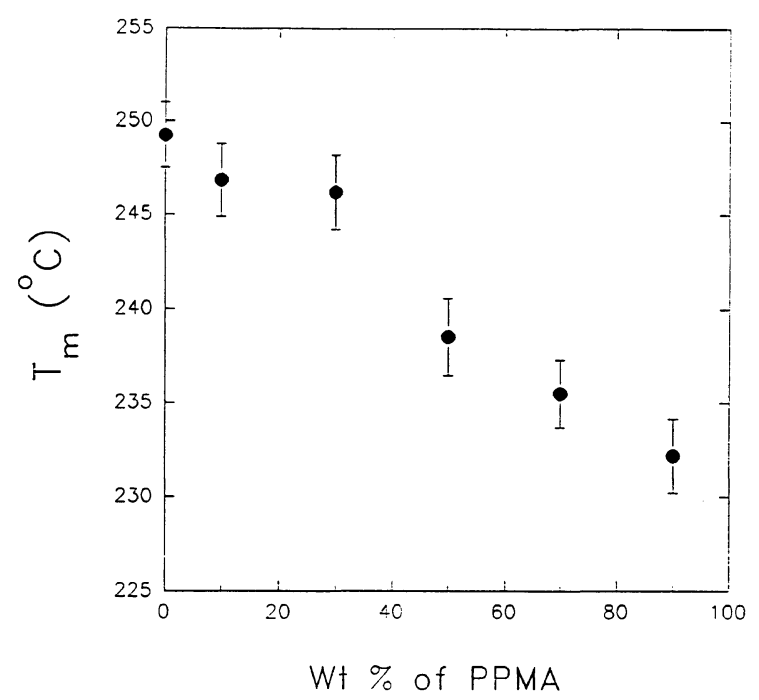

Figure 6. A plot of melting point against PPMA composition.

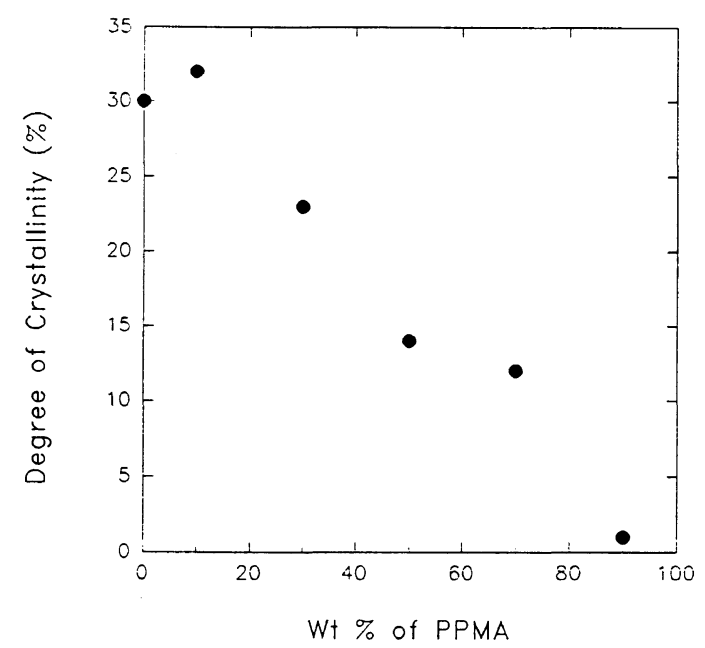

Figure 7. The composition dependence of the degree of crystallinity of PC/PPMA blends calculated from the melting peak of Figure 5.

polymer-amorphous polymer systems, as can be noticed by eq 2 :

$$
\frac{1}{T_{\mathrm{m}}}-\frac{1}{T_{\mathrm{m}}^{0}}=-\frac{R v_{2}}{\Delta H_{2}^{\mathrm{f}} v_{1}} \cdot \chi_{12}\left(1-\Phi_{2}\right)^{2}
$$

Nishi et al. ${ }^{27}$ derived eq 3 to get a linear relationship between $\left(1 / T_{\mathrm{m}}-1 / T_{\mathrm{m}}^{0}\right)$ and $\left(\Phi_{1}^{2} / T_{\mathrm{m}}\right)$ :

$$
\frac{1}{T_{\mathrm{m}}}-\frac{1}{T_{\mathrm{m}}^{0}}=-\frac{B v_{2}}{\Delta H_{2}^{\mathrm{f}}} \cdot \frac{\Phi_{1}^{2}}{T_{\mathrm{m}}}
$$

Table III describes the calculation procedure of $\chi_{12}$ for the blends. In order to obtain quasi-equilibrium melting temperature of pure PC, the annealing condition was set at $190^{\circ} \mathrm{C}$ for $72 \mathrm{~h}$ in solution state as in the case of PC-PPMA blend. In this situation, melting temperature of pure $\mathrm{PC}$ was not increased above $249^{\circ} \mathrm{C}$ for further annealing. Thus, we took this quasi-equilibrium melting temperature of $\mathrm{PC}$ as $249^{\circ} \mathrm{C}$ to evaluate interaction parameter. It should be mentioned that the equilibrium melting temperature of $\mathrm{PC}$ used in this work to calculate interaction parameter in eq 3 is not real one but quasi-equilibrium melting temperature. Although the 
Table III. Calculation of $\chi_{12}$ from the melting point depression in Figure 5

\begin{tabular}{|c|c|c|c|}
\hline \multicolumn{4}{|c|}{$\begin{array}{l}T_{\mathrm{m}}^{0}=522 \mathrm{~K} \\
v_{1}=134 \mathrm{~cm}^{3} \mathrm{~mol}^{-128} \\
v_{2}=195 \mathrm{~cm}^{3} \mathrm{~mol}^{-128} \\
\Delta H_{2}^{\mathrm{f}}=33.5 \mathrm{~kJ} \mathrm{~mol}^{-1}=8040 \mathrm{cal} \mathrm{mol}^{-128}\end{array}$} \\
\hline$\Phi_{1}$ & $T_{\mathrm{m}} / \mathrm{K}$ & $\Phi_{1}^{2} / T_{\mathrm{m}}$ & $1 / T_{\mathrm{m}}-1 / T_{\mathrm{m}}^{0}$ \\
\hline 0.1 & 518 & $0.193 \times 10^{-4}$ & $0.148 \times 10^{-4}$ \\
\hline 0.3 & 515 & $1.748 \times 10^{-4}$ & $0.260 \times 10^{-4}$ \\
\hline 0.5 & 512 & $4.882 \times 10^{-4}$ & $0.386 \times 10^{-4}$ \\
\hline 0.7 & 508 & $9.651 \times 10^{-4}$ & $0.528 \times 10^{-4}$ \\
\hline 0.9 & 502 & $16.10 \times 10^{-4}$ & $0.803 \times 10^{-4}$ \\
\hline
\end{tabular}

The plot of $\left(1 / T_{\mathrm{m}}-1 / T_{\mathrm{m}}^{0}\right)$ vs. $\left(\Phi_{12} / T_{\mathrm{m}}\right)$ gives a slop. By using the least square fit, slop $=-B v_{2} / \Delta H_{2}^{\mathrm{f}}=0.0391 ; B=-1.612\left(\mathrm{cal} \mathrm{cm}^{-3}\right)$; $\chi_{12}=B v_{1} /(R T)=-0.21\left(\right.$ at $\left.249^{\circ} \mathrm{C}\right)$.

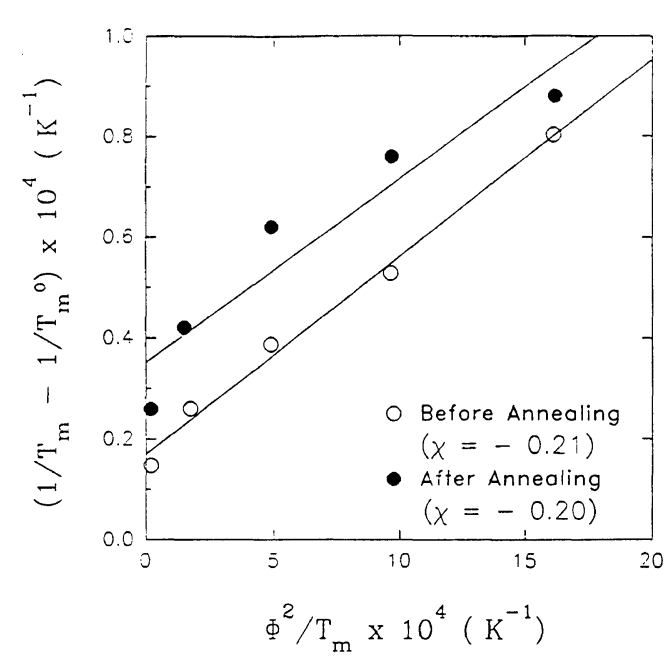

Figure 8. A plot of $\left(1 / T_{\mathrm{m}}-1 / T_{\mathrm{m}}^{0}\right)$ vs. $\Phi_{1}^{2} / T_{\mathrm{m}}$.

present quasi-equilibrium melting temperature cannot be considered general in application to calculation of interaction parameter, it should be capable of lending insight to the interpretation of the melting temperature depression data of this work. $\left(1 / T_{\mathrm{m}}-T_{\mathrm{m}}^{0}\right)$ against $\Phi_{1}^{2} / T_{\mathrm{m}}$ was plotted as shown in Figure 8 and $\chi_{12}$ of -0.21 was obtained for the non-annealed blends. For the blends annealed at $190^{\circ} \mathrm{C}$ for 3 days, $\chi_{12}$ is -0.20 . Almost same values of $\chi_{12}$ for either case indicate that there may occur no change of interaction by annealing. Anyway, the negative value of $\chi_{12}$ indicates that there is some interaction between PC molecules and PPMA molecules.

It is desirable to get a more reliable equilibrium melting temperature of pure PC and identify the reason for the miscibility of the blends in future work. The value of $\chi_{12}$ of PC/PPMA blends obtained by $T_{\mathrm{m}}$ depression should be verified by a small angle neutron scattering (SANS) technique.

\section{CONCLUSION}

The sheets of PC and the blends were best crystallized by soaking in THF in the volume ratio of $1: 3$ polymer: solvent. In the case of pure PC the degree of crystallinity of $30 \%$ was obtained. The PC crystallized by THF vapor alone resulted in incomplete spherulitic crystals (sheaf-like). These vapor induced PC showed lower crystallinity and melting point than those crystallized by soaking in THF. The gradual lowering of the melting point and crystallinity of the blends with increasing PPMA content were observed when the blends were crystallized by THF. However, an exception occurred for the 90/10 PC/PPMA, whose crystallinity is a little higher than that of pure PC. This is probably due to the nucleating effect by PPMA which accelerates the rate of crystallization. The interaction parameter, $\chi_{12}$, was calculated by melting point depression method and its value was -0.21 at $249^{\circ} \mathrm{C}$. For the blends annealed at $190^{\circ} \mathrm{C}$ for 3 days, the value of $\chi_{12}$ increased to -0.20 , indicating no effect of annealing on the value of $\chi_{12}$. The negative value of $\chi_{12}$ implies that there is some interaction between PC and PPMA.

\section{REFERENCES}

1. W. Seibourg, Kunststoffe, 76(10), 917 (1986).

2. W. Seibourg, H. Schmid, F. M. Rateike, S. Andres, and U. Grigo, Polym. Eng. Sci., 30, 1133 (1990).

4. G. Kömpf, H. Löwer, and M. Witman, Kunststoffe, S. 76(11), 1077 (1986).

5. J. Hening, Kunststoffe, 75(7), 19 (1985).

6. M. Pietralla and Th. Picper, Coll. \& Polym. Sci., 268, 797 (1990).

7. H. Nakamoto and H. Fukushima, Eur. Patent Appl., EP 154,136 (1985).

8. N. Narumi, S. Kamiya, and M. Sugimura, Brit. UK Patent Appl., GB 2,089,523 (1982).

9. Hoya Lens Crp., Jpn. Kokai Tokkyo Koho, JP 59 07,901 (1984).

10. K. Sasagawa, T. Hyugaji, and M. Imai, PCT Int. Appl. WO 8400,370 (1984).

11. N. Darumi, S. Komiya, and M. Sugimura, Ger. Offen., DE 3,146,075 (1982).

12. Y. Nakai, Y. Shimomura, and Y. Matsumoto, Jpn. Kokai Tokkyo Koho, JP 61 42,602 (1986).

13. Y. Nakai, Y. Shimomura, and Y. Matsumoto, Jpn. Kokai Tokkyo Koho, JP 61 36,307 (1986).

14. Nippon Sheet Glass Co., Ltd., Jpn. Kokai Tokkyo Koho, JP 6023,408 (1985).

15. Y. Kanemura, M. Imai, and K. Sasagawa, Ger. Offen., DE 3,439,935 (1985).

16. T. Fukuda, Eur. Patent Appl., EP 59,561 (1982).

17. Jpn. Kokai Tokkyo Koho, JP 63227,603 (1988).

18. B. Konishi, Jpn. Kokai Tokkyo Koho, JP 61 40,194 (1986).

19. T. Kyu, D. Park, and W. Cho, J. Appl. Polym. Sci., 44, 2233 (1992).

20. R. P. Sheldon and R. R. Blakey, Nature, 195, 172 (1962).

21. A. Misra and R. S. Stein, J. Polym. Sci., Polym. Lett., 10, 473 (1972).

22. G. Peilstöker, Brit. Plast., July, 365 (1962).

23. L. Bottenbruch, Farbenfabriken Bayer A. G., "Encyclopedia of Polymer Science and Technology," Vol. 10, Interscience, New York, N.Y., 1969, pp 710-764.

24. D. R. Paul and J. O. Altamirano, Polym. Prepr., Am. Chem. Soc., Div. Polym. Chem., 15, 409 (1974).

25. F. Gallez, R. Legras, and J. P. Mercier, Polym. Eng. Sci., 16, 276 (1976).

26. P. K. C. Pillai, G. K. Narula, and A. K. Tripathi, Polym. J., 16, 575 (1984).

27. T. Nishi and T. T. Wang, Macromolecules, 8, 909 (1975).

28. D. W. Van Krevelen, "Properties of Polymers," 3rd ed, Elsevier, New York, N.Y., 1990, pp 82-121. 